\title{
Training and teaching applications for Autistic Children based on C\# standalone application
}

\author{
Mohammed J. Yousif ${ }^{1, *}$, S.M. Shadman Shahriar ${ }^{2}$, Al-Waddah Al-Abdulsalam ${ }^{2}$,Khalil Ibrahim Al-Farsi ${ }^{2}$ \\ Department of Computer Science, Memorial University of Newfoundland \\ ${ }^{2}$ Department of Computer Science, Sohar University \\ *Corresponding author: Mohammed J. Yousif ${ }^{1}$, malmutoory@mun.ca
}

\begin{abstract}
Autism is a disease, which affects the child's ability to communicate with those around them and develop mutual relations with them and hence it needs to have a quick and efficient treatment technique. The earliest age of ASD diagnosis is between 4.5 and 5.5 years. Approximately 6 per 1000 children under eight years suffer from ASD. Statistics show an annual increase of the disease about 3,500 cases of children with autism in the Sultanate of Oman. The aim of this work is to design an Interactive Learning System based Windows Application for teaching the children with Autism. The Windows Application is developed using C\# which will be useful to teach the children different things such as Alphabets, Numbers, Fruits, Vegetables and many more. The application is a bi-lingual application (English and Arabic). The application can be used also to test the progress of the children. Also, develop interactive materials that help children with special needs for enhancing their communicating and thinking. In addition, develop interactive materials that help children with special needs for enhancing their communication and rational skills which could help them to integrate into the society.
\end{abstract}

Keywords: teaching method; autism; programming language; teaching based on computer; student attitude. 


\section{Introduction}

Autism Spectrum Disorders (ASD) a developmental and neurological disorder whose symptoms mainly comprise of difficulty in socialization and communication. These symptoms lie on a spectrum, which means there are various severities of ASD. The main part of the brain that is usually affected is the cerebellum, which is usually irregular both functionally and neurologically (Vellonen \& Virnes, 2012). Nearly about third of children with autism seem to miss skills in their second year. Approximately 6 per 1000 children under eight years suffer from ASD. Different Methodology uses to act with ASD including studies, diagnostic practice, and an expert (Robins et al., 2009). The researchers concluded that ASDs have a difference of causes, but they agree that ASD affects the same brain systems (Ismail et al., 2012; Shamsuddin et al., 2012). Moreover, the interview and observational methods have clear advantages and disadvantages using social robot (Yousif J., 2021; Yousif M., 2021). Retrospective reporting may be hard for parents of older offspring. The observations in clinical environments can miss key features. An acceptable approach would combine an interview and observational measures.

Autism is a disease, which affects the child's ability to communicate with those around him and develop mutual relations with them. The prevalence of ASD is around 1\%, and recent estimation of undiagnosed cases increases it to $1.5 \%$ in the UK (Baron-Cohen et al., 2009). Also, about one-third of parents of children with ASD noticed a problem before their Childs first birthday, and $80 \%$ saw problems by 24 months. The earliest age of ASD diagnosis is between 4.5 and 5.5 years. ASD incidence greatly depends on gender, therefore; about four times more boys have autism than girls. In the United States, statistics denote that a child in every 91 children diagnoses with ASD. Moreover, in Malaysia, a child in every 150 children has ASD problem. The increasing prevalence of ASD in different countries all over the world, it is understandable that the need for effective intervention for ASD to be classified as a public health emergency.

Statistics show an annual increase of the disease about 3,500 cases of children with autism in the Sultanate of Oman. Despite differences in the seriousness of the symptoms of autism from case to case, but the patients with autism have difficulties in their mutual social relations, language, and behavior.

With the explosion in popularity in the use and development of programs for all sorts of jobs/functionality, it is no surprise that there was also development of applications to help/ aid in the therapy and education of autistic children. These apps are very flexible and can be built in all sorts of different ways with different interfaces, different teaching materials and even accept input from the user in various different ways (keyboard/mouse, touch, microphone, camera), 
depending on the student's needs. Many researchers discussed, proposed and implemented various different solutions for teaching and educating children with autism.

A paper by Wojciechowski, discussed the use of a mobile application to help with the teaching of children with autism. The system is based on Estimote Beacon programmable sensors and an accompanying mobile application, which teaches the children about certain words' pronunciation and meaning. A parent/ guardian is required to navigate the application and to ensure that the system is working accordingly. This system was tested on two autistic children (a boy and girl aged 4.5 and 3.5 years old respectively), and they found that there were noticeable improvements in the children's speaking abilities as well as their understanding of certain words (Wojciechowski \& Al-Musawi, 2017).

Zakari, designed and deployed a systematic review of several different games that were designed to help in the education and therapy of children with autism. They found that these applications generally helped in improving various aspects of autistic children, such as communication, socialization, and imagination. They also found that most of these applications focused on improving social as well as communication skills, and the most popular forms of input for these programs are keyboard/mouse and touchscreen (Zakari \& Simmons, 2014). Schuller, implemented an interactive virtual environment for developing autistic children's social and academic skills. Keyboard/mouse, facial recognition, gesture recognition and voice recognition can all be used as forms of input for this program, each with their own accompanying exercises so that all skills can be tested and trained. Their results showed that children with ASD showed significant gains in their socialization and emotional cognition abilities, and they performed better overall in tests than the children who did not use this program. Data from these participants was then used to further improve the program (Schulleret et al., 2015).

Another paper by Hourcade, developed sets of applications that run on tablets that help with improving autistic children's social skills. These applications were developed after working with autistic children and their teachers. 26 participants took part in this experiment, 16 elementary school children and 10 middle school children whose levels vary on the autism spectrum. Their results concluded that the children were showing more communicative expressions, meaningful improvements in coordination and collaboration and were engaging more frequently in social behaviors after using these programs (Hourcade et al., 2012).

The aim of this work is to design a comprehensive Learning System Based on a standalone application for children with autism. Also, develop interactive materials that help children with special needs for enhancing their communicating and thinking. For example, teaching directions up, down, left and right or responding to various 
commands such as sitting, standing, walking, and lifting objects after recognition and other actions. These interactions between the child and the standalone application will help to increase the communication skills and accepting instructions fast.

Figure 1 shows the prevalence of autism in children around the world. It can be seen that there is a significant increase of $176 \%$ in the number of children with autism per 1000 children from 2002 (6.7 cases) to 2016 (18.5 cases).

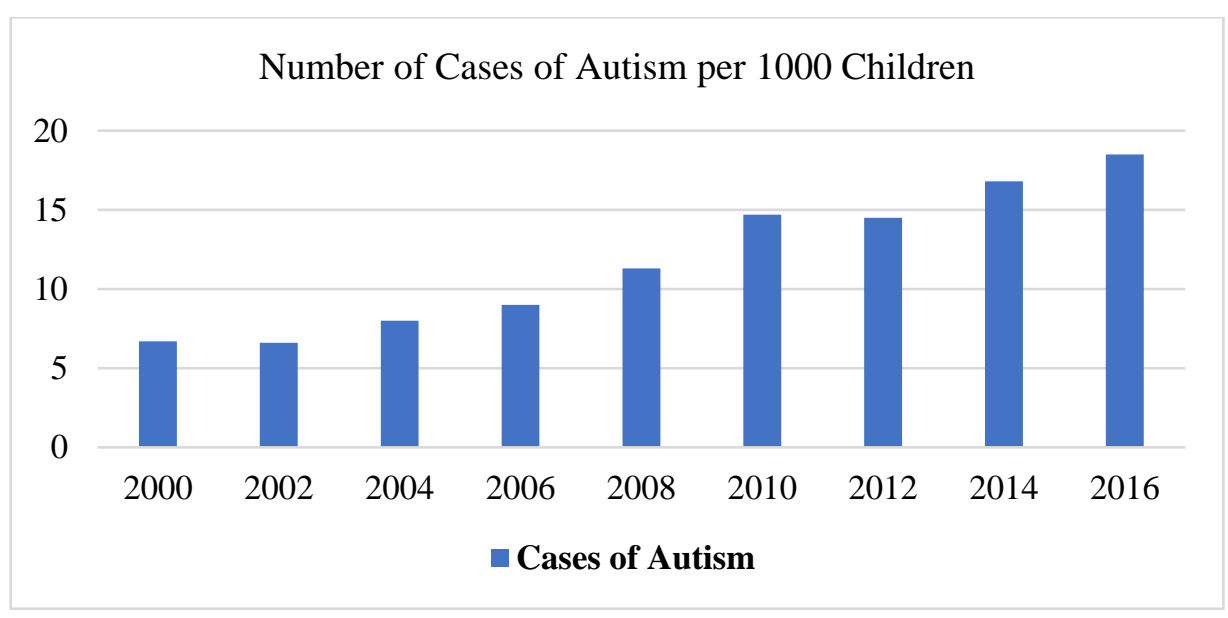

Figure 1. The autism statistics prevalence of children CDC. (2021).

Despite differences in the seriousness of the symptoms of autism from case to case, but the patients with autism have difficulties in their mutual social relations, language, and behavior.

The aim of this work is to design a teaching and learning framework for children with Autism based on a standalone program. Also, develop interactive materials that help children with special needs for enhancing their communicating and thinking. For example, teaching directions up, down, left and right or responding to various commands such as sitting, standing, walking, and lifting objects after recognition and other actions. These interactions between the child and the standalone application will help to increase the communication skills and accepting instructions fast.

\section{Problem Statement and Work Significance}

According to TACA (The Autism Community in Action), there was a significant increase in the number of cases of autism to 1 in 59 children in 2018, when compared to prior years (Curing, 2021). More and more researchers are focusing on finding new methods for autism therapy and treatment, since finding a method that is cost effective, accessible to the majority of people and viable is a crucial step in dealing with this increase in autism cases. These method's effectiveness can then be tested with autistic children in specialized clinics under the direct supervision of 
pediatric specialists. However, educating children is very complex, time consuming, expensive and relies on many variables that need to be taken into consideration. One such method that has been devised is the use of standalone applications based Natural language processing that help the student's concentration, socialization and communication skills (Yousif, 2013). This is done by incorporating interesting and interactive exercises which can be interacted with using a variety of different input devices (keyboard/mouse, touch, microphone). This can help with accessibility and the engagement of the student during the therapy sessions. This paper aims to study and analyze previous papers on this topic, and use the key findings from that analysis to develop a standalone application that is suitable for helping autistic children with their communication and social skills.

Statistics indicate an increase in the number of people with autism in the Sultanate of Oman. This increase in the number of people infected with ASD should have a corresponding increase in the methods of handling and treat the patients. As well as, the high cost of therapy in specialized centers is being a significant problem.

Also, it will increase the communication skills between children using new technologies. This system will help Omani families and society by treating patients with autism at a low price and rehabilitating them in the society. In addition, it will reduce the cost of treatment by offering and implementing free programs for children with autism based on the use of the latest scientific and practical methods. Support children with Autism to restore normal life and practice regular activities and then integrate them into society is much needed.

\section{Research Methodology}

This project will follow qualitative research methods to build a complete frame for teaching kids with Autism. The project is a multi-discipline which it involves activities related to several fields of computing and information technology like the design and implements some interactive materials for kids who has a need. Whereas, the practical phase will start with the design and implementation of interactive materials for teaching and learning of kids with special needs. Then design and implement the framework for teaching children with autism-based C\# application. The framework will use these interactive teaching methods and classroom activities motivated children with autistic spectrum, for improving their learning and attainment. Once the framework becomes ready for proper testing, an evaluation by running sets of tests and acquired results will be analyzed and discussed. Finally, adequate reporting of findings will be carried out. Figure 2 show the proposed system Architecture that describes the interaction of outside entities with a system, or subsystem 


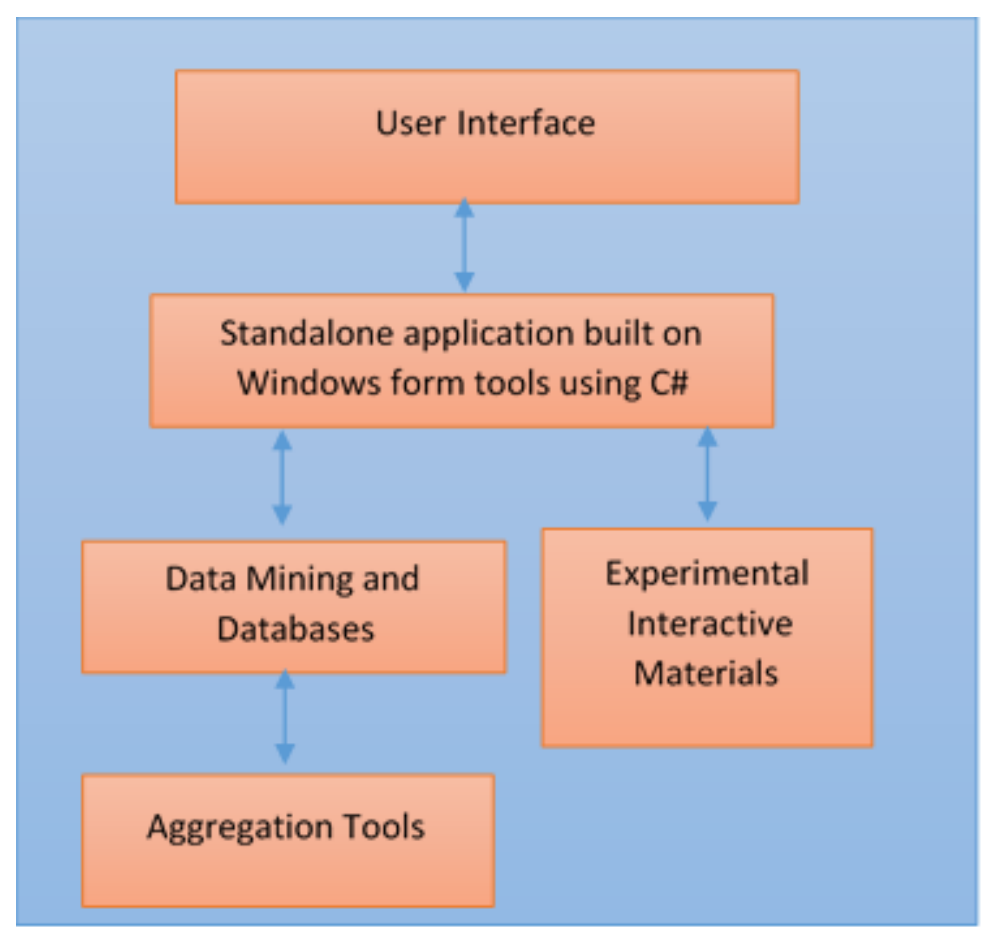

Figure 2. proposed system Architecture

\section{System Implementation \& Testing 4.1. System Implementation}

The program consists of several key components that together provide the user with a suitable learning experience. First, the user interface is built in an intuitive and easy to use manner with two languages in mind, English and Arabic. This is so that both local and international students can use this application Only the essentials are included so as to avoid confusion when navigating the GUI and to avoid unnecessary resource usage. One of the primary goals of this application is for it to be able to work on most computers so it is accessible to as many people as possible (Saini, 2021). This application is more accessible alternative to other therapy methods, such as robots, since robots are much more expensive and their availability is limited to only certain countries. This application has no such limitations, since it can be distributed online effortlessly and can run on most hardware, old or new. Since it is built on the windows form application using C\#, the standalone application is very flexible and can be fine-tuned to the user's needs. The application was built after extensive analysis of other research papers that used a program like this for autism therapy. The code was also written in an optimized manner so as to improve the performance of the application. The experimental interactive materials contain all of the resources that will be taught to the student. It, like other parts of the application, is also flexible and therefore can be changed to suit the student's needs. New learning courses can 
also be added to cover a wider range of subjects. The final segment of this application is the data mining and databases segment. This database contains records for all of the students and their test scores, overall performance, progress in the courses and other important data. This data is then used by the aggregation tools to not only access the data but also to give suggestions to the student on which courses to focus on, which tests they excelled in and other advice to help the student improve in the long term.

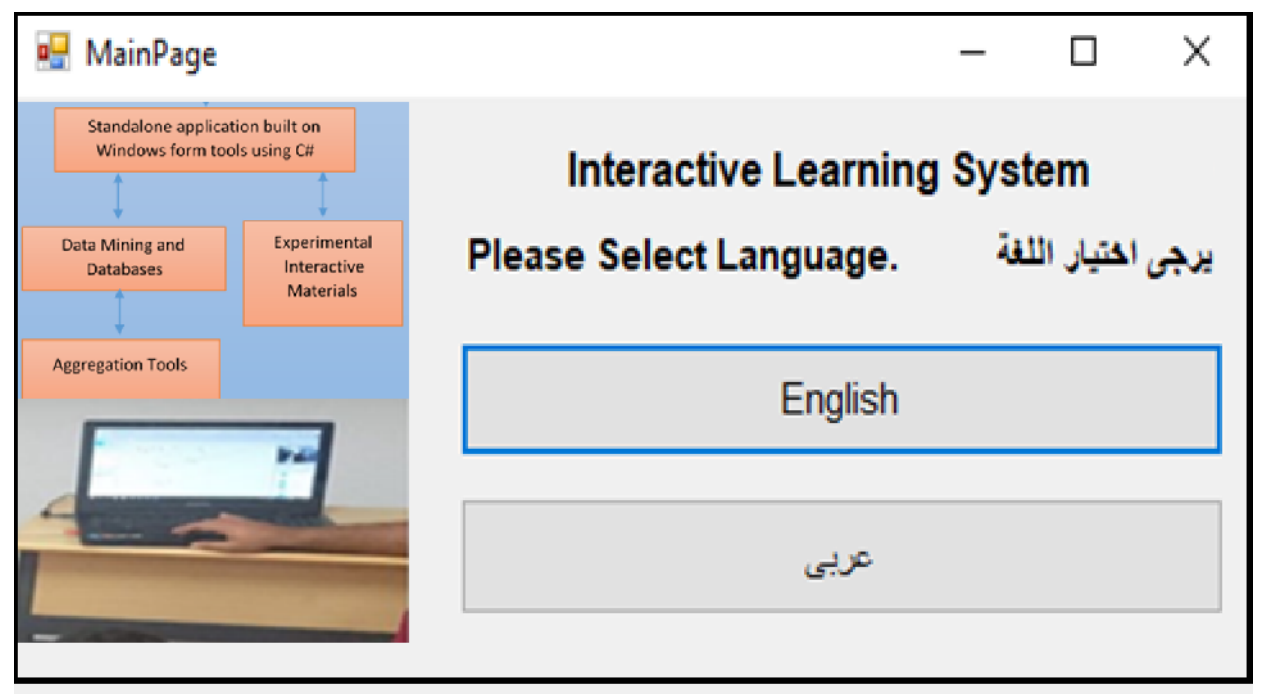

Figure 3. Main screen Form of the proposed system

Figure 3 shows the interface that the user first sees when they open the program. The standalone program as well as its corresponding exercise is built with two languages in mind (English and Arabic), so at the start, the user is prompted to choose between these two languages.

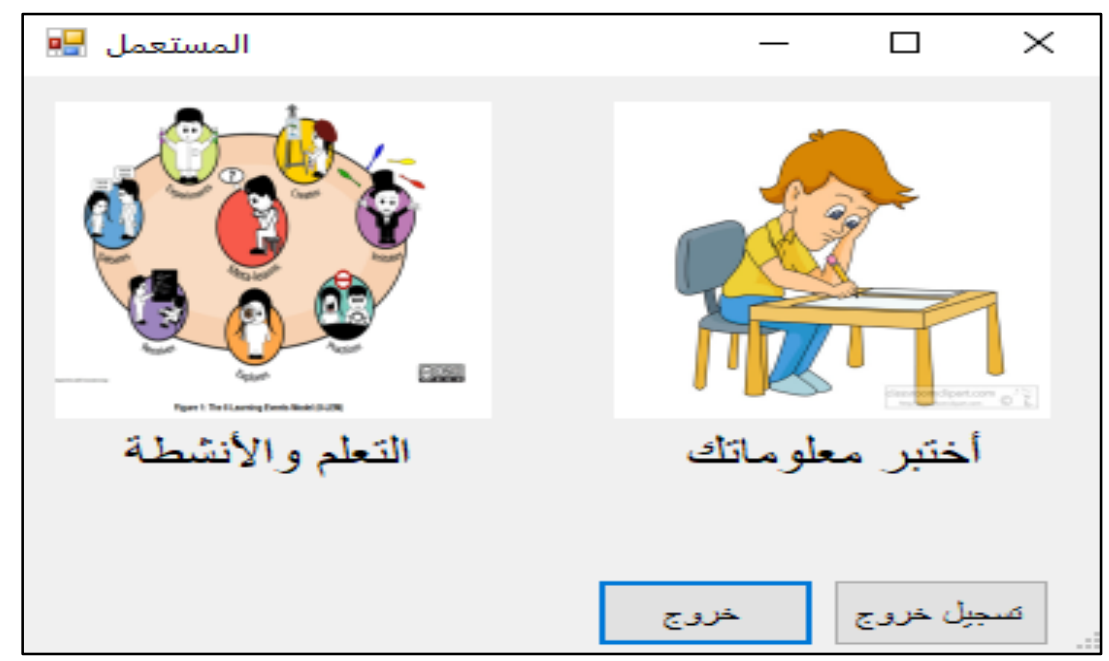

Figure 4. User Home Form 
Figure 4 shows the next screen, which asks the user if they want to take a test, or take part in a learning session. During the experimentation phase, the students were first asked to take the test and these results were recorded. This will help gauge the student's performance prior to intervention. Afterwards, the student takes each learning course at their own pace with the supervision of a trained professional. The standalone application has a built-in database that tracks the progress of each student and which learning courses they completed. Each student has their own profile, and their results/ progress can be accessed at any time. At the end, when the student is finished with all of the learning courses, they will retake the test again. These new results will then be compared to their previous ones to see if there were any meaningful changes in the student's performance and understanding of the subject.

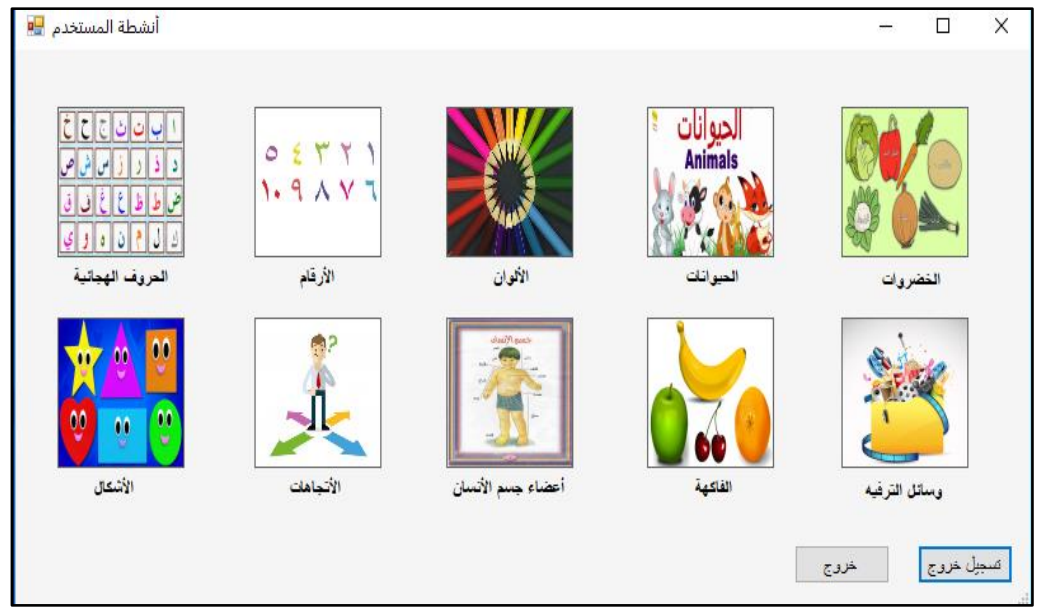

Figure 5. Interactive Learning and Activities Form follows:

Figure 5 shows all of the currently available learning courses. All of the subjects that are being tested are as

- Alphabets

- Numbers

- Colours

- Animals

- Vegetables

- Shapes

- Directions

- Human body parts

- Fruits

- Entertainment

Teaching can be done in two different ways; using a video or using interactive reading. All teaching will be done with the supervision of a trained professional, so the lesson can be paused/ slowed down or something can be explained in further detail if necessary. This standalone application is expandable and flexible, so any number of courses can be 
added if necessary. The courses can also be changed so as to help the student become more comfortable when taking the lesson, depending on their needs.

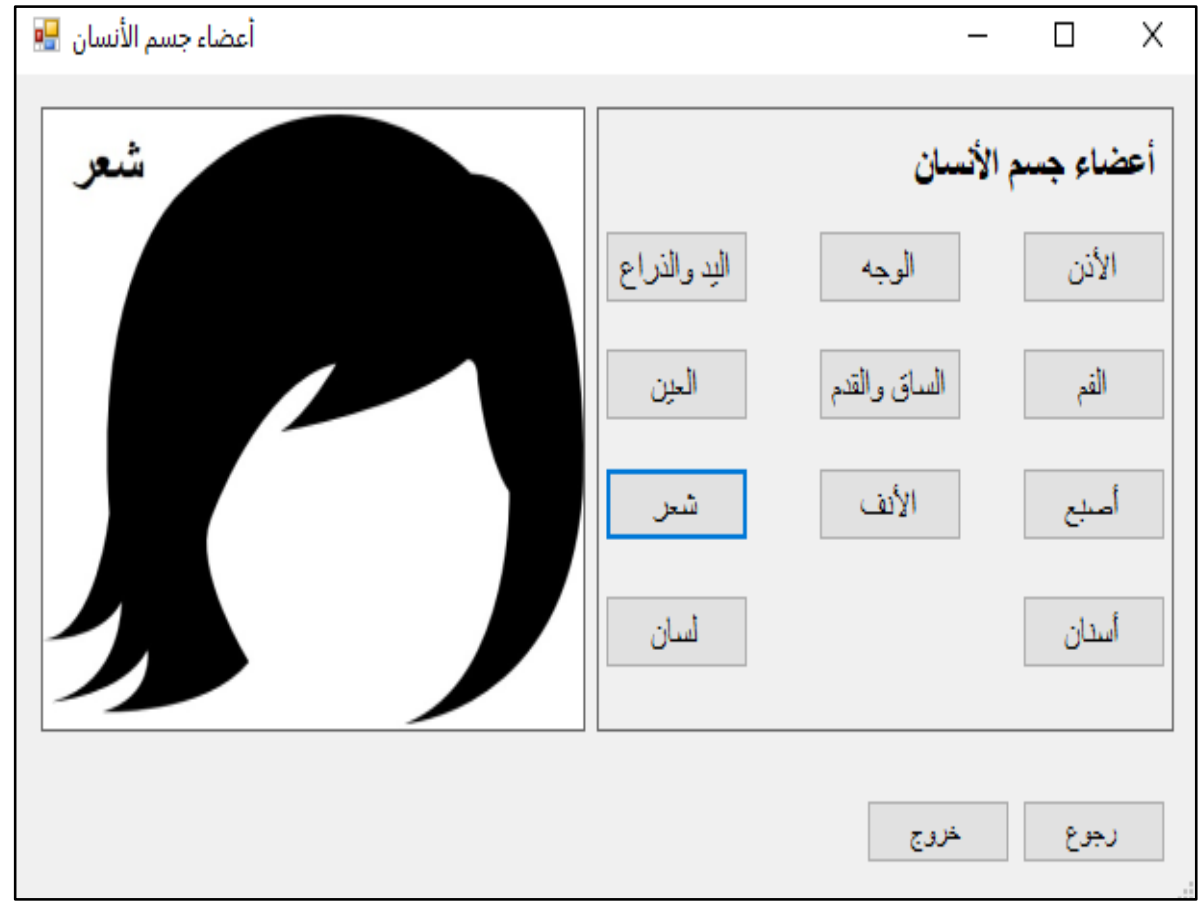

Figure 6. Human Body Parts Learning Form

Figure 6 shows an example of one of the questions in the test. Here, the student is asked to pick the correct word that best represents the picture on the left.



Figure 7. Direction Learning Form 
Figure 7 shows an example of one of the learning courses that involves the use of a video. All media controls are included in the windows so as to allow for fine tuning of the lesson depending on the student's needs (volume, speed, pausing).

\subsection{System Testing}

We have tested our project with the Autistic kids 2 times. Once at an event by Nebras Autism Center at Al-Saham, Sultanate of Oman on the 22nd April 2018 and on 16th May 2018, we invited the Center to bring the Autistic Kids at Sohar University.

The experiment was performed in 3 different stages. In the first stage, the students were immediately asked to take the test as soon as they entered the experimenting facility. This is done to obtain the control results, whose values will be used to determine if the standalone application had any positive effect on the student's performance. In this stage, the students will have to depend on the knowledge that they obtained solely from the therapy sessions with tutors from the clinics. These results will then be stored in the database that is built into the standalone application for later use. Figure 8 shows an example of the results screen.

In total, 6 students took part in this experiment. All of the children and their parents both agreed for this experiment to take place and for data to be collected. All of the children's autism scores were tested at an earlier time by the clinic, and it was found that these children were all at a similar place on the autism spectrum. This means that the results should not be affected by the severity of their condition. Table 1 contains more information about the participants



Figure 8. Result Form after completion of Exam

Table 1. information about the participants 


\begin{tabular}{lll}
\hline Participants & Age & Gender \\
\hline A & $\mathbf{1 0}$ & Female \\
B & 9 & Male \\
C & 9 & Male \\
D & $\mathbf{8}$ & Female \\
E & $\mathbf{8}$ & Male \\
F & 7 & Male \\
\hline
\end{tabular}

In the second stage, the students were then taught all of the learning courses that are available in this application with the supervision of a certified professional. Some of the material that was taught includes, alphabets, numbers, colours, animals and vegetables. After the students were done or felt satisfied with the courses, then they moved on to the third stage.

In the third stage, the students were then asked to retake the tests. This data is also very important for measuring the effectiveness of this standalone application since it will be directly compared to the control data. After all of stages were complete, data comparison using the aggregation tools took place and suitable conclusions about the data were made. Figure 9 represents all of the data for each student, before and after the intervention and Figure 10 shows the participants in the test session.

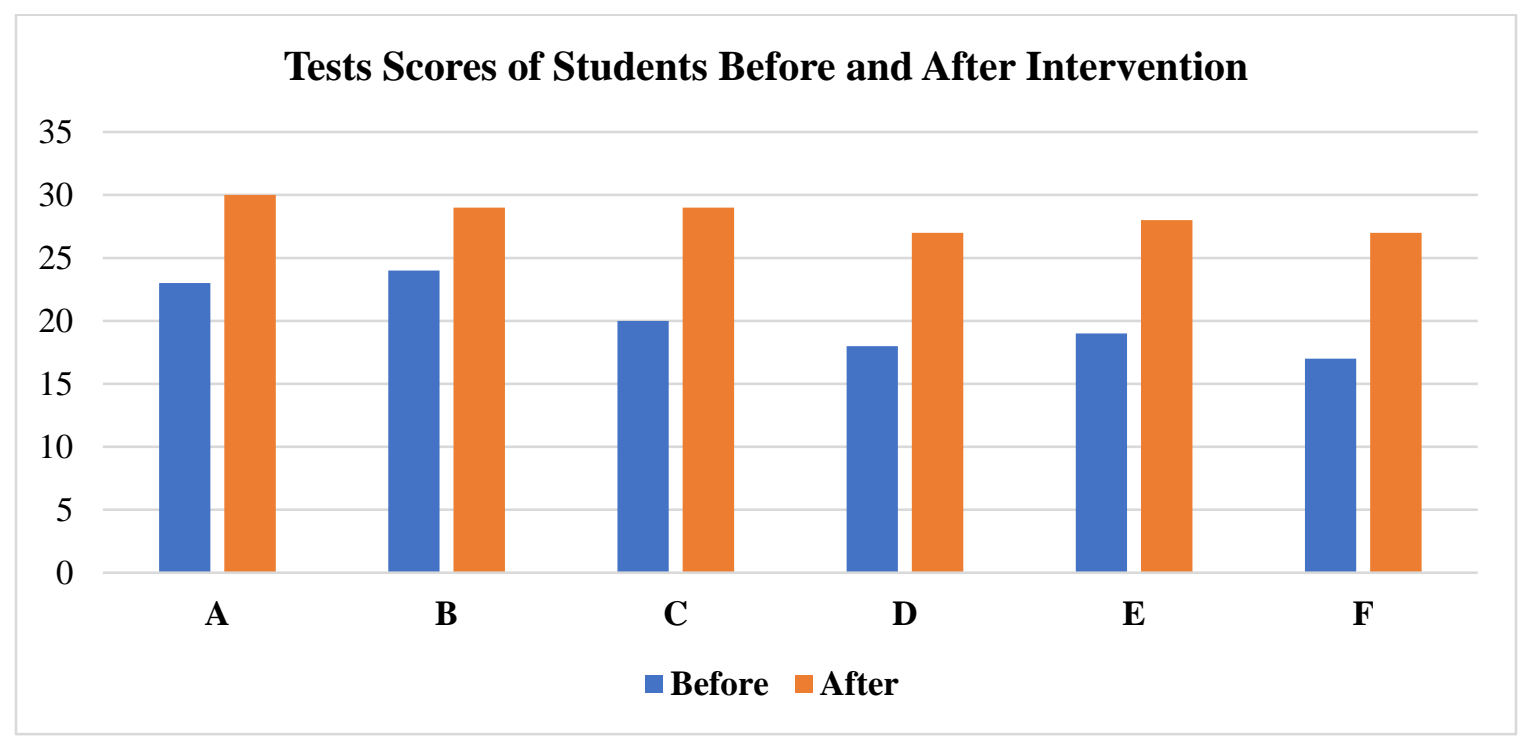

Figure 9. The Tests Scores of Students Before and After Intervention

In Figure 9, it can be seen that the test score was higher for all of the students. There was an average increase of $40.5 \%$ across the board, with the highest increase being student $\mathrm{F}$ with an increase of 58.8\%. After an interview with 
the trained professionals, they stated that the students were much more engaged in the lessons and they were a lot less shy in general.

Overall, the children responded positively to the tests. They said that they had a lot of fun playing with the application because it is interactive and more enjoyable than a regular tutoring session. The teaching staff of the Nebras Autism Centre had some comments like, we needed to implement more exercises in the application and add support for more languages.

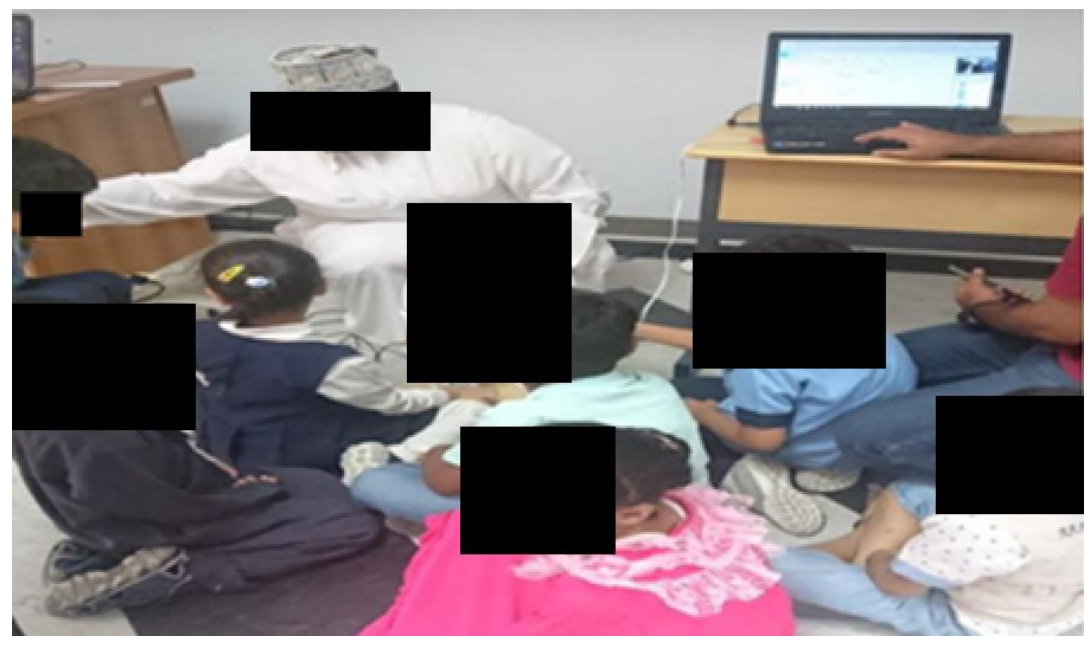

Figure 10. the participant in the test session

\section{Conclusion}

With the high increase in the number of autistic children, it is necessary to work together with parents, educators and children to come up with the best interactive technology to help autistic kids. It is essential to identify the basic needs of suffering children and what can develop their skills.

The result of this work is to show that standalone applications are viable solutions that could play a critical role in improving the autistic children's emotional, social and mental skills. Today, one in 59 children diagnosed with autism spectrum disorder is diagnosed. This is a 78 percent increase in just four years (Cabibihan et al., 2013). This trend has significant implications for the healthcare budget in countries because the constant cost estimates for treatment of ASD patients range from four to six times higher for patients with autism.

The Literature clearly indicates that more work is needed to follow the rapid increasing in the number of kids with autism. Results show that USA had more research for dealing with ASD by 14 research papers including in this survey. England is coming in the second stage with 3 research paper. Also, Spain takes the third place with two 
research papers. The current study gave evidence that therapies based on standalone application helped children with autism spectrum disorder (ASD) more effectively than usual therapy methods. However, this doesn't come without a cost, since developing and implementing these programs requires a lot of effort, expertise and human resources.

\section{Recommendations}

We must meet the needs of all children to ensure that they have a good education so that they have the opportunity to gain self-confidence to show the potential and progress in the education curriculum better and faster. The current progress will not be enough to help these kids completely and hence we must plan to develop our project with more programs and materials.

The following below are our future works on the project:

1. Implement the current project in Virtual Reality using HTC Vive VR headset.

2. Build more interactive materials for the teaching.

3. Add support for other languages besides Arabic and English

\section{Acknowledgment}

The research leading to these results has no Research Project Grant Funding from the Research Council in the Sultanate of Oman, Research Grant Agreement FURAP/SU/17/004. The authors would like to acknowledge support from the Research Council in the Sultanate of Oman.

\section{References}

[1]. Baron-Cohen S., et al. (2009). Prevalence of autism-spectrum conditions. UK school-based population study The British Journal of Psychiatry, 194(6), pp.500-509.

[2]. Cabibihan, J.J., Javed, H., Ang, M. and Aljunied, S.M., (2013). Why robots? A survey on the roles and benefits of social robots in the therapy of children with autism. International journal of social robotics, 5(4), pp.593-618.

[3]. Curing Autism. (2021). AUTISM STATISTICS \& COST. [accessed on 20 March 2021]. https://tacanow.org/autismstatistics/

[4]. CDC. (2021). Data \& Statistics on Autism Spectrum Disorder Online: https://www.cdc.gov/ncbddd/autism/data.html. [Accessed on 20 March 2021]

[5]. Hourcade, J. P., Bullock-Rest, N. E., \& Hansen, T. E. (2012). Multitouch tablet applications and activities to enhance the social skills of children with autism spectrum disorders. Personal and ubiquitous computing, 16(2), 157-168.

[6]. Ismail, L.I., Shamsudin, S., Yussof, H., Hanapiah, F.A. and Zahari, N.I., (2012). Robot-based intervention program for autistic children with humanoid robot NAO: initial response in stereotyped behavior. Procedia Engineering, 41, pp.1441-1447.

[7]. Robins, B., Dautenhahn, K., \& Dickerson, P. (2009, February). From isolation to communication: a case study evaluation of robot assisted play for children with autism with a minimally expressive humanoid robot. In 2009 Second International Conferences on Advances in Computer-Human Interactions (pp. 205-211). IEEE. 
[8]. Schuller, B., Marchi, E., Baron-Cohen, S., Lassalle, A., O’Reilly, H., Pigat, D., ... \& Ligmann, K. (2015). Recent developments and results of ASC-Inclusion: An integrated internet-based environment for social inclusion of children with autism spectrum conditions. In Proceedings of the of the 3rd International Workshop on Intelligent Digital Games for Empowerment and Inclusion (IDGEI 2015) as part of the 20th ACM International Conference on Intelligent User Interfaces, IUI 2015 (pp. 9pages).

[9]. Shamsuddin, S., Yussof, H., Ismail, L.I., Mohamed, S., Hanapiah, F.A. and Zahari, N.I., (2012). Initial response in HRI-a case study on evaluation of child with autism spectrum disorders interacting with a humanoid robot Nao. Procedia Engineering, 41, pp.1448-1455.

[10]. Saini, D. K. (2021). Fuzzy and Mathematical Effort Estimation Models for Web Applications. Applied computing Journal, $10-24$.

[11]. Vellonen, V., Kärnä, E., \& Virnes, M. (2012). Communication of children with autism in a technology-enhanced learning environment. Procedia-Social and behavioral sciences, 69, 1208-1217.

[12]. Wojciechowski, A., \& Al-Musawi, R. (2017). Assisstive technology application for enhancing social and language skills of young children with autism. Multimedia Tools and Applications, 76(4), 5419-5439.

[13]. Yousif, J. H. (2021). Social and Telepresence Robots a future of teaching. Artificial Intelligence \& Robotics Development Journal 1 (1), 58-65

[14]. Yousif, J. H. (2013). Natural language processing based soft computing techniques. International Journal of Computer Applications, 77(8).

[15]. Yousif, M. (2021). Viability of Robots in Improving Autistic Student's Engagement and Happiness When Learning. Artificial Intelligence \& Robotics Development Journal, 26-42.

[16].Zakari, H. M., Ma, M., \& Simmons, D. (2014, October). A review of serious games for children with autism spectrum disorders (asd). In International conference on serious games development and applications (pp. 93-106). Springer, Cham.

(C) () Author(s) and ACAA permit unrestricted use, distribution, and reproduction in any medium,
provided the original work with proper citation. This work is licensed under Creative Commons Attribution
International License (CC BY 4.0).

